\title{
Proceeding
}

Supplementary Issue: Summer Conferences of Sports Science. Costa Blanca Sports Science Events, 20-21 September 2019. Alicante, Spain.

\section{Review on study of sporting activity for the reaches school learning}

\author{
DAVIDE DI PALMA ${ }^{1}$, FRANCESCO PERROTTA2 ${ }^{2}$ DOMENICO TAFURI ${ }^{1}$ \\ ${ }^{1}$ Parthenope University, Naples, Italy \\ 2M.I.U.R. Campania, Italy
}

\begin{abstract}
The threshold of attention is valid for all types of contexts that the child faces from an early age, one of these is their academic performance that often, due to the inability to concentrate, is scarce and obstacle to the relationship between problematic child and his peers and adults. No responsibility is ascribable to children because, certainly, they are suffering from a neuropsychological disorder, nor are they the parents' fault. The pathology that has found space is ADHD (attention deficit and hyperactivity disorder: attention deficit and hyperactivity). It is one of the most frequent neuropsychological disorders of the developmental age, which occurs in pediatric age, characterized by a level of inattention and by a series of secondary seconds that denote hyperactivity and impulsivity. Children with ADHD cannot control their responses to the environment: they are inattentive, hyperactive and impulsive. Such behavior compromises their social and educational life. This pathology is associated, in fact, with disorders of social adaptation, a low level of education and employment, to be considered one of the most important signs, in childhood, of bad psychosocial adaptation in adulthood. The ADHD is too often misunderstood therefore not considered supported by therapeutic interventions. So, the aim of this research in to promote an educational and therapeutic path based on the increase of the hours of sport and motor education (in the extracurricular context) with the aim of improving the attention span, reducing impulsive problems, hyperactivity and stimulating self-control. Keywords: School; Child; Sport; Attention.

Cite this article as:

Di Palma, D., Perrotta, F., \& Tafuri, D. (2019). Review on study of sporting activity for the reaches school learning. Journal of Human Sport and Exercise, 14(5proc), S1963-S1968. doi:https://doi.org/10.14198/ihse.2019.14.Proc5.16

Corresponding author. Parthenope University, Naples, Italy.

E-mail: domenico.tafuri@uniparthenope.it

Supplementary Issue: Summer Conferences of Sports Science. Costa Blanca Sports Science Events, 20-21 September 2019. Alicante, Spain.

JOURNAL OF HUMAN SPORT \& EXERCISE ISSN 1988-5202

(c) Faculty of Education. University of Alicante

doi:10.14198/jhse.2019.14.Proc5.16
\end{abstract}




\section{PURPOSE OF STUDY}

Identify correlation of activity reaches and school learning, from a physical level of attention finalizing the increased performance of learning and optimizing the mental performance through an intervention aimed at increasing psychophysical activities. Physical and Sport activities are very important in these age groups. Today most of childhood people have an attention deficit, and even in these cases the sporting activity is able to support school learning.

\section{RECENT FINDINGS}

Several scientific evidences have shown that physical activity plays a significant role both for the health of the body and the mind. Any physical activity, especially walking and cycling, has positive reverberations on school learning. This is accomplished for several reasons.

First, physical activity stimulates neurogenesis, which is the birth of new nerve cells. It constitutes a mechanism of self-regeneration of the brain. After birth, neurogenesis is particularly active in the cerebral area of the hippocampus. From here the cells produced migrate to other areas of the brain and differ, depending on the location.

Secondly, physical activity increases the release of BDNF, a neurotrophic protein, which implements brain growth processes. In practice, BDNF increases the appearance of dendritic extensions in brain cells and the creation of new synapses between neurons. Several studies have shown that there is a marked correlation between physical activity, BDNF production and learning improvement (Babiloni et al, 2010; Cass, 2017; Conson et al, 2010; Conson et al, 2009; Daenen et al, 2015; Devasahayam, Downer, Ploughman, 2017; Duzel, van Praag, Sendtner, 2016; Macedonia, Repetto, 2017; Mairbäurl, 2013; Mak et al, 2017). In this regard, it has been shown that cycling increases the ability to learn more words in the linguistic field.

In the third instance, physical activity has a significant influence on two brain structures, the hippocampus and the entorhinal cortex, which underlie short-term memory. In practice, body activity increases their volume.

As a fourth element, one can mention the positive role that physical activity plays on cognitive control. With this construct we mean a series of executive functions that have a significant impact on learning, such as attention, reasoning ability, planning ability, problem solving ability, decision-making ability, cognitive flexibility, inhibitory control of distracting stimuli and short-term memory (Marinelli et al, 2017; Mura et al, 2010; Niewada, Michel, 2016; Pistoia et al, 2010; Pistoia et al, 2017; Pistoia, Sacco, Carolei, 2013a).

Lastly, physical activity intervenes on the release of neurotransmitters. Several studies have shown that body activities increase the release of gamma - amino - butyric acid (GABA), a neurotransmitter that has a soothing role towards anxiety and depression syndromes. These clinical frameworks can sometimes undermine learning processes (Pistoia, Sacco, Carolei, 2013b; Sacco et al, 2008). Doing sports or any physical activity 4 hours after studying improves memory and learning. That shows how exercise can improve memory. Above all if carried out after a specific time interval.

Leading the research was a team of experts from Radboud University in the Netherlands that involved 72 people in a memory test. The test consisted of storing 90 image associations for a period of about 40 minutes. 
The volunteers were then divided into three random groups: some performed a physical exercise immediately after the test, others after four days, and others after four hours, as shown in Figure 1.

Physical activity consisted of 35 minutes on the exercise bike at an alternating intensity, which reached up to $80 \%$ of the participants' maximum heart rate.

After two days the volunteers underwent a test to check what they remembered. At the same time, their brains were observed through an MRI scan.

Analysis of the results showed that those who had performed physical activity after four hours from exercise could remember the associations of images better than others. Specifically, the volunteers had experienced a $10 \%$ more memory enhancement than the other test participants.

In according to CONI, in Italy, in the world the programs for sports centres for children of both sexes between 5 and 7 years, provides that in this range the sport is oriented to "Physical-educational" purposes, focusing 'attention on four fundamental points, which describe the characteristics of children in various age groups:

- The auxological factor.

- The psychological-social factor.

- The structuring of basic motorcycle activities.

- The methods of learning.

Let's see the characteristics of each of these:

The auxological factor Between 5 and 6 years in the child there is the first elongation, which is in a thrust in length that affects the bone, rather than the muscular and that is concentrated in the legs. So, it happens that the skeleton increases in weight, the bony levers are stretched without there being, however, an adjustment of muscle strength. The vertebral column may tend to sag, giving rise to attitudes such as kyphosis and scoliosis, since the development is not perfectly symmetrical on the left side and on the right side of the body. From 7 years of age, increase the respiratory capacity, so the spine and the rib cage suffer especially if adequate physical activity is lacking. Since 8 years, however, there is a certain increase in strength and strength that, if carefully guided, leads to a deficiency of previous periods.

The psychological-social factor It is not possible to sum up expectations precisely. A child is even more dangerous for him. However, there is a moral and emotional dependence on adults. The game between children of this age, which is the main way in which social behaviour is manifested, is managed by continuous arguments and physical aggressions, perhaps violent, but of short duration. The ongoing process, however, leads to more and more associative attitudes, within which the children are and suitable for achieving an identical purpose. From 6 years, however, it is about progress in acquiring awareness of one's body and one's psyche. He also begins to see others see him and judge him, then apply to others to be respected and to be held in proper consideration. Reacts to reproaches and gratifications. The seven-year-old shows a considerable interest for his body and for businesses. Its ability to socialize increases, slows down, decreases egocentric tendencies. Finally, at the age of eight, he is perfect for the error, for the user, for self-realization, even in use of the models that the adult gives him.

The structuring of basic activities of motion The child goes through, slowly and throughout the school age, a process of neurophysiological evolution, called "dominance", which usually means that the left side of his body has functions of support, support and defence, while the right has functions of attack, momentum and 
offense. This process originates from the hand and then evolves throughout the body side, up to the so-called "lateralization", i.e. the division of the nervous control side of the two halves of the body. Without the lateralization it is not possible to effectively perform sporting gestures. The child is not born lateralized but becomes it on the basis of the maturation of the nervous structures and until it reaches its body schema and the effectiveness of its movements will be inaccurate. Symptoms are the difficulty in recognizing the above and below, the right from the left, in general the psychomotor disorganization. To these aspects must be added the development of the body schema, that is the self-image that the child has. These are mental images, corresponding to the various positions of the body or parts of the body, both in static and moving positions. It is necessary for the child to experience all the instrumental possibilities of his body: standing, lying, sitting, upside down, in all kinds of movement, rolling, falling, and so on. It occurs in phases: distinction between the self and the non-self, recognition of one's own image in the mirror, and so on. Also, the complete acquisition of the body schema is obtained at the end of the school age. Lateralization, body schema, spacetemporal organization, are the conditions and the result of the child's maturation. Lateralization, as a neurophysiological process, has important implications for the other two, which are more typically psychological. Teachers, animators, sports educators must favour this aspect of cognitive development. However, the necessary neuro-psychological and affective presuppositions exist, which depend on respect for the times and the evolutionary deadlines that cannot be anticipated, but only facilitated, prepared. Proposing a child to an activity, that is, a type of cognitive experience, for which it is not yet mature can be not only unproductive, but even counterproductive. In fact, the child chooses times and ways of his interests. This brings us directly to the fourth point.

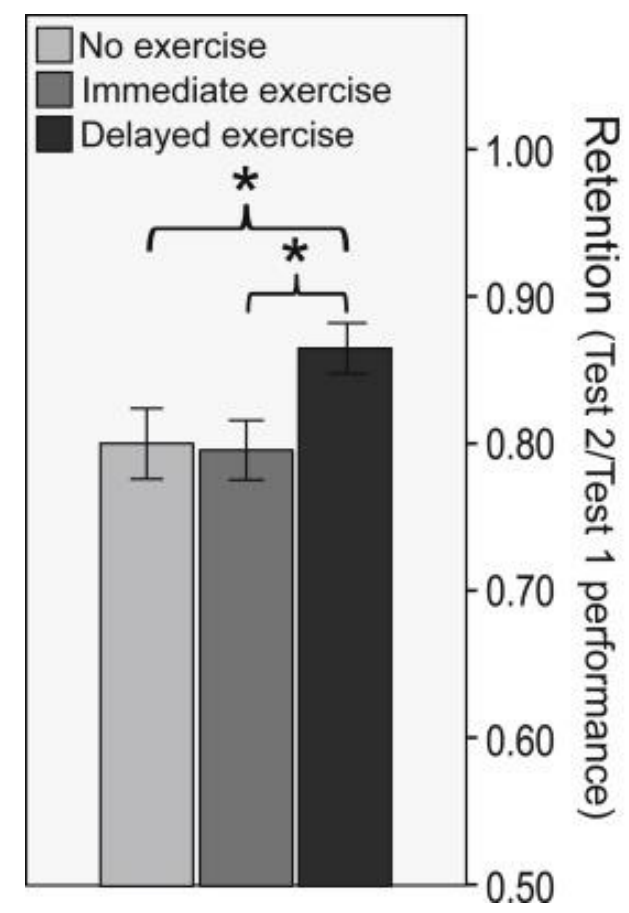

Figure 1.

Learning methods It must be borne in mind that motor learning by imitation is not always profitable and profitable for the child. The student, in fact, can perform motor gestures only if previously he has been placed in a position to have learned simpler and elementary motor experiences. Learning every gesture can be impossible if the child has not learned simpler gestures that act as "bricks" to build the most complex one. So, the traditional process of teaching motor gestures: "to demonstrate" - "to perform" - "to correct" may not 
be the most correct, also because it could give rise to situations full of anxiety or frustration. The goal, therefore, is to route the student on the path of a good motor execution, so that the child acquires mastery of gestures. From the age of five, therefore, motor learning must always take place gradually and favouring spontaneous and individual expression, in a joyful and playful way. Children learn from their mistakes. An important characteristic of the teacher, therefore, must be that of not underlining the error or correcting it, but of stimulating the self-corrective skills of the student, inserting motivating elements for attention and repetition, also to prevent the child, overwhelmed by failure or frustration and reproach, withdraw from repeating the experience.

Seventy-two participants were randomly assigned to one of three age- and gender-matched groups; all learned 90 picture-location associations over a period of approximately $40 \mathrm{~min} n$ each group, half of the participants started at 9 a.m. and half at 12 p.m. to control for time-of-day effects. Following a baseline cued recall test (test 1), participants in the immediate exercise (IE) group performed a 35-min interval training on an ergometer at an intensity of up to $80 \%$ of their maximum heart rate.IE participants subsequently moved to a separate quiet environment for a 3-hr delay period, where they watched nature documentaries, before returning to the exercise lab for a control session. This control session did not involve exercise but used the same context otherwise. For the delayed exercise (DE) group, the protocol was identical but with the order of the exercise and control session reversed; for the no exercise (NE) group, both sessions before and after the delay period were control sessions. Participants returned to the lab $48 \mathrm{hr}$ after initial encoding and performed a second cued recall test (test 2) in the magnetic resonance (MR) scanner. With this design, we could investigate whether post-learning physical exercise affected memory retention, whether its effects were time dependent, and whether our intervention influenced the neural substrate of memory retrieval as measured using fMRI. The study was approved by the local ethics committee (CMO Region ArnhemNijmegen, the Netherlands).

\section{CONCLUSION}

The conclusions we have found in these studies have been very positive, since it has been found that the healthy and balanced physical activity in children is able to raise the threshold of attention, also due to a systemic vasodilatation that leads to a greater flow of blood and nutrients to the brain, this way we are faced with discoveries that may be an integral part of a school system, where it would be appropriate to increase the number of hours a week of physical education, because in addition to an increase in performance there would be undisputed benefits under each point of view, the physical, the mental, the social (integration of group sports that are predisposing to group work).

\section{REFERENCES}

Babiloni C., Pistoia F., Sarà M., Vecchio F., Buffo P., Conson M., et al. (2010). Resting state eyes-closed cortical rhythms in patients with locked-in-syndrome: an EEG study. Clin. Neurophysiol. 121, 18161824. https://doi.org/10.1016/j.clinph.2010.04.027

Cass S. P. (2017). Alzheimer's disease and exercise: a literature review. Curr. Sports Med. Rep. 16, 1922. https://doi.org/10.1249/JSR.0000000000000332

Conson M., Pistoia F., Sarà M., Grossi D., Trojano L. (2010). Recognition and mental manipulation of body parts dissociate in locked-in syndrome. Brain Cogn. 73, 189-193. https://doi.org/10.1016/i.bandc.2010.05.001 
Conson M., Sarà M., Pistoia F., Trojano L. (2009). Action observation improves motor imagery: specific interactions between simulative processes. Exp. Brain Res. 199, 71-81. https://doi.org/10.1007/s00221-009-1974-3

Daenen L., Varkey E., Kellmann M., Nijs J. (2015). Exercise, not to exercise, or how to exercise in patients with chronic pain? Applying science to practice. Clin. J. Pain. 31, 108-114. https://doi.org/10.1097/ajp.0000000000000099

Devasahayam A. J., Downer M. B., Ploughman M. (2017). The effects of aerobic exercise on the recovery of walking ability and neuroplasticity in people with multiple sclerosis: a systematic review of animal and clinical studies. Mult. Scler. Int. 2017:4815958. https://doi.org/10.1155/2017/4815958

Duzel E., van Praag H., Sendtner M. (2016). Can physical exercise in old age improve memory and hippocampal function? Brain 139, 662-673. https://doi.org/10.1093/brain/awv407

Macedonia M., Repetto C. (2017). Why your body can jog your mind. Front. Psychol. 8:362. https://doi.org/10.3389/fpsyg.2017.00362

Mairbäurl H. (2013). Red blood cells in sports: effects of exercise and training on oxygen supply by red blood cells. Front. Physiol. 4:332. https://doi.org/10.3389/fphys.2013.00332

Mak M. K., Wong-Yu I. S., Shen X., Chung C. L. (2017). Long-term effects of exercise and physical therapy in people with Parkinson disease. Nat. Rev. Neurol. 13, 689-703. https://doi.org/10.1038/nrneurol.2017.128

Marinelli L., Quartarone A., Hallett M., Frazzitta G., Ghilardi M. F. (2017). The many facets of motor learning and their relevance for Parkinson's disease. Clin. Neurophysiol. 128, 1127-1141. https://doi.org/10.1016/i.clinph.2017.03.042

Mura E., Lanni C., Preda S., Pistoia F., Sarà M., Racchi M., et al. . (2010). Beta-amyloid: a disease target or a synaptic regulator affecting age-related neurotransmitter changes? Curr. Pharm. Des. 16, 672683. https://doi.org/10.2174/138161210790883723

Niewada M., Michel P. (2016). Lifestyle modification for stroke prevention: facts and fiction. Curr. Opin. Neurol. 29, 9-13. https://doi.org/10.1097/wc0.0000000000000285

Pistoia F., Carolei A., Sacco S., Sarà M. (2017). Commentary: embodied medicine: mens sana in corpore virtuale sano. Front. Hum. Neurosci. 11:381. https://doi.org/10.3389/fnhum.2017.00381

Pistoia F., Conson M., Trojano L., Grossi D., Ponari M., Colonnese C., et al. . (2010). Impaired conscious recognition of negative facial expressions in patients with locked-in syndrome. J. Neurosci. 30, 78387844. https://doi.org/10.1523/ineurosci.6300-09.2010

Pistoia F., Sacco S., Carolei A. (2013a). Behavioral therapy for chronic migraine. Curr. Pain Headache Rep. 17:304. https://doi.org/10.1007/s11916-012-0304-9

Pistoia F., Sacco S., Carolei A., Sarà M. (2013b). Corticomotor facilitation in vegetative state: results of a pilot study. Arch. Phys. Med. Rehabil. 94, 1599-1606. https://doi.org/10.1016/j.apmr.2013.01.019

Sacco S., Sarà M., Pistoia F., Conson M., Albertini G., Carolei A. (2008). Management of pathologic laughter and crying in patients with locked-in syndrome: a report of 4 cases. Arch. Phys. Med. Rehabil. 89, 775-778. https://doi.org/10.1016/i.apmr.2007.09.032

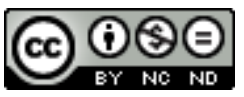

This work is licensed under a Attribution-NonCommercial-NoDerivatives 4.0 International (CC BY-NC-ND 4.0). 